\title{
'A day to day struggle': A comparative qualitative study on experiences of women with endometriosis and chronic pelvic pain
}

Mike Armour ( $\square$ m.armour@westernsydney.edu.au )

Western Sydney University https://orcid.org/0000-0001-7539-9851

Alexandra Hawkey

Western Sydney University https://orcid.org/0000-0003-0851-9117

Sowbhagya Micheal

Western Sydney University

Helene Diezel

University of Queensland https://orcid.org/0000-0002-6696-2996

K Jane Chalmers

Western Sydney University https://orcid.org/0000-0001-6991-559X

\section{Research Article}

Keywords: Endometriosis, chronic pelvic pain, diagnostic delay, stigma, chronic pain

Posted Date: March 2nd, 2021

DOI: https://doi.org/10.21203/rs.3.rs-289745/v1

License: (9) This work is licensed under a Creative Commons Attribution 4.0 International License.

Read Full License 


\section{Abstract}

There is an increasing body of research that considers the lived experiences of women with endometriosis. However, less attention has been paid to women's lived experiences with nonendometriosis related chronic pelvic pain (CPP). The aim of this study was to explore similarities and differences in experiences of women with endometriosis and non-endometriosis related CPP. A total of 17 participants aged between 21 and 48 years old participated in three focus groups between June 2017 and February 2018. Using thematic analysis three main themes were found. In "the struggling women" women with both endometriosis and non-endometriosis related CPP described the impact that pain had across significant aspects of their lives including; intimate relationships, fertility, parenting and work. In the "unheard women", participants shared similar accounts of not being listened to or taken seriously by healthcare professionals leading to incorrect or delayed diagnosis, and unnecessary treatments. In the final theme, "the self-silenced women" all participants described how a societal normalisation of heavy menstrual bleeding, pelvic pain and dyspareunia led to women to silence their experiences. While all women wanted to resist such silencing through information and support seeking, women with nonendometriosis related CPP described fewer avenues to accessing credible resources or networks for support. Greater awareness, education and support resources are needed for women who experience nonendometriosis related CPP.

\section{Introduction}

Chronic pelvic pain (CPP) in women is a term that encompasses a range of conditions, including endometriosis, vulvodynia, painful bladder syndrome, adenomyosis, and chronic pelvic inflammatory disease ${ }^{1}$. CPP is characterised by intermittent or constant pain below the umbilicus that is unrelated to pregnancy or normal menstruation, and lasts over six months ${ }^{2}$. Primary symptoms of CPP include pain either during or in the 24 hours following sexual activity (dyspareunia), painful urination (dysuria), pain during menstruation (dysmenorrhoea), and pain outside menstruation (non-cyclical pain) ${ }^{3,4}$. CPP is also commonly associated with feelings of fatigue, anxiety, and depression ${ }^{5}$. Many women report social isolation, difficulties with sexual intimacy, and decreased work productivity ${ }^{6}$, all of which contribute to decreased health-related quality of life ${ }^{4,7}$. Interactions with health care providers for women with CPP often tend to be unsatisfactory ${ }^{8}$, with pain often not being taken seriously or alternate diagnosis such as irritable bowel syndrome being given 9,10 .

Chronic pelvic pain is highly prevalent, affecting more than one in five Australian women ${ }^{11}$. Endometriosis and vulvodynia are two of the most commonly diagnosed CPP conditions in women of reproductive age, with estimated lifetime prevalence rates of around $11 \%$ in Australia ${ }^{12}$ and $8-16 \%$ for vulvodynia ${ }^{13,14}$.

Endometriosis advocacy and lobbying in Australia has resulted in the first Australian National Action Plan for Endometriosis ${ }^{15}$, with significant funding being allocated to increase awareness of endometriosis, 
reduce diagnostic delay and increase treatment options for women with endometriosis. There has been previous research into the lived experience of endometriosis in Australian women ${ }^{8}$, however, women with CPP who do not have a diagnosis of endometriosis have received much less attention both in Australia and worldwide ${ }^{16}$. Given quantitative data from Australia shows a similar healthcare burden ${ }^{17}$ and similar impact on their social, sexual, and academic lives ${ }^{6}$, it is important to explore any differences in the lived experience of these two cohorts of women with CPP.

In this study we used focus groups to explore any similarities and differences in experiences of women with endometriosis and non-endometriosis related CPP. This information could provide a better understanding on the women's journey through the healthcare system, the impact a diagnosis, or lack of, might have, and to help identify similar and dissimilar experiences between the two cohorts. This information will allow us to better support women and ensure adequate support and resources exist, regardless of the cause of the CPP.

\section{Materials And Methods}

\section{Study Design}

This research was approved by the Western Sydney University Human Ethics committee (H12019) in January 2017. This study was part of a larger national program of research which explored the impact of chronic pelvic pain and endometriosis in women in Australia. The quantitative results of the survey component of the study including the cost of illness burden ${ }^{17}$ and on diagnosis and impact ${ }^{6}$ have been published. This article reports on the qualitative component of the study, which utilised focus groups to explore in depth women's lived experience with endometriosis or CPP.

\section{Participants and Procedure}

Participants were recruited utilising a number of avenues. Firstly, at the end of the Australian EndoCost survey women were invited to indicate whether they would be interested in participating in a focus group. In addition, the research team's personal and professional networks were used as part of a snowball sampling strategy to disseminate the invitation to those who did not fill in the survey; this included social media postings by Endometriosis Australia, Pelvic Pain Foundation of Australia, and EndoActive, the three largest support and advocacy groups in Australia at that time, with over 50,000 combined followers on social media.

Three focus groups were conducted between June 2017 and February 2018, one conducted online comprising of five women with non-endometriosis related pelvic pain, and two conducted in person in Sydney comprising of women with endometriosis. The seventeen participants were aged between 21 and 48 and on average participants were 32 years old.

Face-to-face focus groups took place at a metropolitan location that was convenient to women. This included a library and community centre. Prior to completing the focus group women were provided with 
written and verbal information about the study outlining the study aims and involvement requirements. All participants provided informed consent to participate by signing a consent form. Focus groups were audio-recorded and lasted between 90 to 110 minutes.

\section{Analysis}

Thematic analysis was utilised to analyse focus group data ${ }^{18}$. All audio transcripts from interviews were professionally transcribed verbatim, and integrity checked for accuracy. Analysis was inductive, with the development of themes being data driven, rather than based on pre-existing research or theory. Firstly, two members of the research team read through all of the focus group transcripts, noting down key concepts or descriptive codes that were present in the data. These concepts or 'initial codes' were then collapsed and refined through discussion with the broader research team to formulate the coding framework. The coding framework was then uploaded onto the computer software NVivo and the entire data set was coded by (HD). A senior member of the research team (MA) read through all coded data to ensure consistency in coding across the data set. Individually the research team then read all of the coded data and came together to discuss central themes, that is concepts or similarities across the data ${ }^{18}$. Through a process of discussion and refinement, using a thematic map, three key central themes were apparent in the data, as discussed below. When presenting data, participants are identified as "EP" or "PP", to distinguish whether women were in endometriosis pain or pelvic pain focus groups. Pseudonyms have been allocated to all focus group participants.

\section{Results}

Analysis of data from both women with pelvic pain disorder and endometriosis revealed complementary themes. The results from both participant groups are presented together to compare women's perspectives across each of the themes below. These include; The Struggling Woman, The Unheard Woman and The Self-Silenced Women.

\section{The 'Struggling' Woman}

Across accounts from women with both pelvic pain and endometriosis, pain was described as "absolutely horrendous", "agonising", "excruciating" and "so intense". For many women, "the pain impacts everything you do" (Tara, EP) and "really invades a vast majority of my life" (Elise, PP). However, the areas that women most commonly found "hard", "tough" and "struggled" with were sexual intimacy, fertility, parenting, and work.

Kate (PP), described her sex life with her husband as a "day-to-day struggle" and that for her, sex "hurts every time. It's never been really a super positive experience but I just have to get through it." Similar sentiments were reflected in Elise's (PP) account, for her negotiating painful sex as a newlywed was, "one of our biggest struggle[s] just because you go into marriage with these expectations". Women with endometriosis similarly described sex as "not enticing" due to pain. Amy (EP) told us, "all those years of it hurting, in your brain, [your] automatic response is, "No, thank you. I don't really feel like it because it's 
going to hurt." For some women, not being able to have sex impacted on both their current and future relationships. Tara (EP) described that her "relationships suffer" because she tries to "keep everybody away" when she is experiencing pain, and Juliette (PP) said, "like dating relationship[s], that's a constant, when do I bring this up, how do you mention that sex is off the cards?" A number of women also described the impact that avoiding sex, or not being able to have sex, had on their sense of self and identity as a woman. Participants said, "you feel awkward because everyone is naked and you've just proved that you're not a woman, nothing there is working" (Ella, EP) and that not being able to have sex "impact[s] your self-confidence... [it's] almost an area to avoid because you don't want to necessarily have these conversations or face the rejections" (Juliette, PP).

Addressing fertility issues was a struggle that was consistently brought up among women with endometriosis. Participants told us, "infertility is one of the hardest things" (Amy, EP) and that "I was diagnosed when I was 17 . It's affected my life really severely. I've had lots of miscarriages. I've had a lot of trouble when I was falling or trying to fall pregnant" (Sarah, EP). While infertility was less often brought up amongst women with pelvic pain, Elise (PP) reflected how the "flow on effect" from her vulvodynia pain has impacted on her capacity to become a mother. She said,

The flow on effect from that lack of sex life which is my husband and I would really love to start a family but, you know, we can't, and l've got friends all around me having babies and that side of it is really very tough to deal with. The pelvic pain as a whole really invades a vast majority of my life.

While some participants successfully conceived through IVF, their struggles with infertility contributed to women feeling "defeated", with some describing its negative impact on their mental health. As Sarah (EP) said, "the mental health... having so many miscarriages, I think that really messed with my head".

Where women did have children, the impact of pain on women's capacity to parent was discussed across both groups. Alison (PP) told us, "my two boys... when they were young...I couldn't even pick them up, and they would see their mother lying on the couch in pain...every single day for six years". Similarly, Tara (EP) described,

I have three boys and we'd wrestle, but I always have a sore tummy and I feel like such a horrible mum because l'll suddenly go, "No, you don't. You can't touch my tummy." We've just been having the best time l'm suddenly in all of this agony, and it ruins the moment...it stops all of that connection.

The ability to parent was particularly compromised when women who had endometriosis needed to take strong pain medication. Nicole (EP) adopted the position of a "terrible" and "disgraceful" mother after forgetting to put the rail up on her child's cot because she was in so much pain and taking strong pain medication. She said;

I know that makes me sound like a really terrible mother that I did that... I just think you're a disgrace as a mother that you did that, and all because of pain that I don't know how to manage it any other way, I don't 
know what to do. So that's my biggest thing that I can't be the mother that I thought I would be and that I wanted to be.

In a similar account Natasha (EP) described sacrificing taking pain medication so that she could drive to pick her daughter up from school, saying, "When I've had an attack at work and she [co-worker] was like, "Oh, have you got pain?" I'm like, "Yeah, I do but I can't drive home if I take that", and I've got a two-year old daughter so I have to pick her up and then I have to function with her." The inability to be the mother that women wanted to be resulted in distress, with women feeling "sad", "horrible", "disappointed" and as though "they were letting their children down" (Tara, EP).

Across both groups of women, participants frequently described that pain significantly impacted on their ability to work, resulting in lost opportunity. Lucy (EP) said, "I get five minutes an hour to get up and go for a walk, so it's really difficult. I'm in a lot of pain, I'm so uncomfortable, even when I do my heat pack" and Elise (PP) told us, "if I'm having a really bad flare up day, my vulval pain, it just distracts me, it's horrible constantly sitting there at the back of your head, like you've got this burning." For some participants, the chronic pain they endured meant they could not go for a promotion or had to leave their chosen career pathway. For instance, Holly (EP) said, "One of the things that upset me the most was I actually had to quit my job as a police officer in [city name] because my endo was so bad" and Alison (PP) described,

I have not been able to work full-time, I have not been able to pursue my career...I had often been asked to take on the role of becoming an assistant principal. I have not been able to and I have not been able to tell anybody why either.

As eluded to in Alison's comment, what made matters worse for both groups of women, but particularly women with pelvic pain, was their inability to communicate to their colleagues why they could not work. Emma (PP) for example, said she struggled to tell colleagues why she needed to miss a meeting, telling us, "I'm not going to sit here and go, "actually, guys, I can't come into this meeting because l've got chronic urethral pain...I feel like I'm weeing razor blades" and Juliette (PP) said, "you can't just say to your boss "Hey, look, I need to go home because my vagina is burning," I can't say that." In many instances, this led to women silencing their pain in the workplace.

\section{The Unheard Woman}

Women with both pelvic pain and endometriosis described a long journey to diagnosis, with some women still experiencing undiagnosed pelvic pain. For instance, women said, "it was a long story to being diagnosed" (Alison, PP), "eight years later is when I found out it was all from endo" (Amy, EP) and "I don't really have a diagnosis... It's been a long road" (Kate, PP). For many women, not being listened to and having their pain being dismissed resulted in a delayed diagnosis. Despite women across groups describing knowing that "something is not right" (Elise, EP) women were told by family or healthcare professionals that, "I was hypochondriac" (Tara, EP), that it "it wasn't that bad" (Sarah, EP), and that "people assume that women or females exaggerate the pain" (Elise, PP). Where no explanation for women's pain was seemingly apparent by healthcare professionals, their pain was often completely 
dismissed, as Kate (PP) said, "my local gynaecologist just thought it was all in my head I think, which is really painful". Internalising this diagnosis left women feeling as though they were "absolutely crazy because no one believes that you're in pain" (Tara, EP) and that "you'd start to believing that you were crazy and it was all made up" (Susan, EP). Even when women did receive a diagnosis, for some women across groups, it "took ages to come to terms" with the diagnosis (Elise, PP), positioning it as "really confronting" (Emma, PP) and the "most devastating thing" (Susan, EP). For women with endo, it was more likely to be positioned paradoxically, both a "relief" because they now had "permission to feel sick" (Michelle, EP) but also "devastating", as women realised they had a chronic disease with "no set thing [treatment]" (Susan, EP) for cure.

Across both participant groups, women also described a lack of 'deep' listening from healthcare professionals when they were describing their symptoms. For example, Alison (PP) said, "my GP continuously for four or more years kept telling me it's simply referred back pain... I'm telling them that I have got deep, deep abdominal pain...for them to simply say, "Oh yeah, it's just referred back pain" and Rosa (EP) telling us, "[the doctor] was like, 'I think you've got malaria', I worked in Kenya and had malaria... I'm like, 'I can definitively tell you I know what malaria feels like. This is not malaria."' Not having symptoms listened to meant that many women experienced multiple incorrect diagnoses, as women told us, "I kept getting told I had UTI" (Anna, EP), "the registrar in the ED department told me I had an infection...probably just ingrown hair" (Natasha, EP), "a doctor tells me I had Chlamydia" (Susan, EP) and "It's because you are overweight" (Tara, EP).

In many instances, these misdiagnoses led to unnecessary drugs or invasive procedures, and distress. Participants told us, "[the doctor] was saying it [chlamydia] was some special strain and I had to put acid suppositories into my vagina...it was the worst thing l've ever seen in my life" (Susan, EP), "I still spent about a year on antibiotics which probably did me a lot of damage" (Anna, EP) and "the amount of different treatments I had...pudendal nerve block, I had Botox, I had some pulsed radiofrequency "(Kate, PP). For some participants, this led to significant mistrust in healthcare professionals, with Tara (EP) telling us, "I just had more surgery that just made things worse. I've got adhesions, I've pleural endometriosis now which is everywhere, and I don't trust anyone. I don't want to go see doctors" and Nicole (EP) saying she tries to "to avoid doctors now. I'm just so sceptical because everything I do it just ends up worse."

Contrary to women's experiences above, some participants did describe positive experiences with healthcare professionals. The key commonalties across women's accounts was the importance of empathetic care, underpinned by being listened to and feeling "heard". As Elise (PP) told us, "thankfully I found a GP and she's been really good all along, as in she listens and she's quite empathetic... they don't minimise pain and that they really listen" and Kate (PP) described,

My specialist now...they're kind of the opposite...you go there and you feel like you're being heard...they're trying their best to understand and piece all the pieces of the puzzle together, rather than just clutching at straws. 


\section{The Self-Silenced Woman}

Across participant's accounts, women spoke of the normalisation of sexual pain and menstrual pain by doctors and other women in their lives. This meant that when women did experience pain, they silenced their concerns and were less likely to seek help. The normalisation of sexual pain was brought up across both groups of women but was particularly apparent among women with pelvic pain. For instance, Kate (PP) said, "when I started to try to have sex and it was quite painful...I realise[d] that things weren't quite right...advice from my friends and even mum [was] to maybe just keep trying to make it better." In a similar account Elise (PP) described trying to have sex on her honeymoon, telling us,

It was very agonising and not pleasant, the worst holiday l've ever had in my entire life. But shortly after that, we battled through for a little while, maybe a month or so trying to work out what was going on. Again, I had mum in my life and ladies saying, "Oh, it's normal to have pain."

Menstrual pain was similarly normalised, with Amy (EP) saying, "pain for me was normalised, I didn't really pursue having it looked after or checked" and Susan (EP) telling us, "I thought it was normal up until last year when - last year it got worse and I was taking like two days off each month." The normalisation of menstrual pain was often reinforced by mothers, when they too had experienced difficult menstrual cycles. As Nicole (EP) described,

My mum started early, had a lot of problems, early menopause, all the rest of the hormonal imbalances, my sisters also both have it. Because my mother experienced a lot of pain, a lot of bleeding, it was normal for her...there was like, "Yeah, stay home," but there wasn't like, "Let's investigate this further," because in her mind it was normal.

The sociocultural silencing of women's bodies, particularly with regard to reproductive health also contributed to women having limited health literacy, including not knowing about their anatomy or what was "normal" menstrual pain or bleeding. Elise (PP) described, "I'm ashamed to say it, before I started going down the journey of getting help for this pain, I didn't know about how my body works and I didn't know anything". Women told us that, "no one really talked about it. They said you bleed and that's it. No one said it was painful, no one said it was heavy" (Tara, EP), and that "it's always been like, "You're on your period, don't talk about it, just deal with it," type of thing and so you never learn about it" (Lucy, EP). For participants who experienced pelvic pain, fear of judgment and embarrassment acted as a further mechanism to silence women's experiences. This for some women, led to feelings of isolation or not being able to reach out for support. As Alison (PP) said, "I don't talk about it at all...it is secret women's business... It's shocking...So it's secret and it shouldn't be" and Juliette (PP) said,

I was too embarrassed or too confronted by my condition to even tell anyone...I didn't tell friends or family or anyone else because - I don't know if it's because it was sex related or vagina related, but for some reason I just didn't know how to open my mouth and either ask for help or express what was going on. 
In contrast to the accounts of silencing above, some women, especially participants with endometriosis, described talking about their condition and reaching out to seek support. Many women with endometriosis described seeking support from online forums, Facebook, or reaching out to leading advocates; "there's Facebook groups as well Endometriosis and Me, and Endometriosis Australia" (Lucy, EP); “Facebook groups completely rescued me...Jill from Endo Warriors, oh my God, she runs this group that's international on Facebook and if you message her, she will respond to you personally about any questions" (Susan, EP). While women with endometriosis described that they "feel like there's like an endo movement really starting...everybody is talking about" (Nicole, EP), it was apparent that less avenues for support were available for women with pelvic pain. Participants with pelvic pain did seek support from online Facebook pages and found this helpful, but for some, the sharing of "negative stories...I find that it fuels my symptoms and fuels my anxiety, which then fuels my urethral burning" (Emma, PP). Women with pelvic pain also described more commonly that when reaching out they, "found it really, really hard to find credible information online... it's so hard to find something that's decent and credible" (Kate, PP), or that resources were "very general and very broad" (Juliette, PP) and that reading available information on Google, "scared me" (Alison, PP).

\section{Discussion}

Using a qualitative approach, this study aimed to explore similarities and differences in the lived experiences of women with pelvic pain and endometriosis.

Our findings mirror recent quantitative research which highlights that chronic pelvic pain and endometriosis impact women across varied life domains at a similar level ${ }^{6}$. Our findings support past endometriosis literature which highlights the profound impact that pelvic pain and other endometriosis symptoms have on all aspects of women's lives ${ }^{6,19-22}$. However, we also found that the impact of CPP was far beyond the effect of pelvic pain on penetrative sex and intimate relationships, which has been the focus of literature examining conditions such as vulvodynia ${ }^{23,24}$. Our findings show that like endometriosis, chronic pelvic pain has a significant impact on other aspects of women's lives including fertility, parenting and work.

Women with chronic pelvic pain and endometriosis often report significant issues with work; mostly due to absenteeism or presenteeism $17,25,26$. Women in our study in both cohorts reported that the taboo nature of menstruation was a key factor in not being able to discuss their need for sick leave. While the taboo on openly discussing menstruation itself is well known and often causes women to self-silence ${ }^{27}$, 28 , women with chronic pelvic pain conditions such as vulvodynia had even more difficulty, as they had to speak specifically about pain or discomfort in their genitals themselves. Women with genital pain struggle to discuss their pain with romantic partners, friends, family, and colleagues, often attributing this difficulty to embarrassment and the taboo surrounding sex ${ }^{29,30}$. While there is an increasing debate on the potential benefits and harms of menstrual leave ${ }^{31}$, it is unclear if women with non-menstrual pelvic pain would be covered by such leave or if they would feel they were entitled to it. 
Women who experienced pelvic pain and endometriosis related pain reported its negative impact on their capacity to parent, as has been reported previously among women with chronic diseases ${ }^{32}{ }^{33}$. Women in our study positioned themselves as 'terrible' mothers, due to limitations in their mothering associated with chronic pain or pain medication. Adopting this position reflects normative cultural constructions of motherhood, where "good" mothers are expected to be self-sacrificing and always physically or emotionally available to meet their children's need ${ }^{34}$. Where women do not meet these idealised discourses of motherhood due to chronic ill health, they may report feelings of failure and psychological distress ${ }^{32}$, as was reported by women in our study.

While there are a number of prominent endometriosis support, education and advocacy groups in Australia who often have educational and awareness programs ${ }^{35,36}$, the same is not the case for women with pelvic pain who have far fewer groups and overall less representation on social media. This was reflected in our participants difficulties finding relevant and reliable information online. A lack of tailored information and support for pelvic pain could lead to isolation, poor support networks and lack of coping skills ${ }^{7}$. Lack of reliable information is especially concerning given that over half of young Australian women report non-cyclical pelvic pain at least once per month ${ }^{37}$, but often report they think it is not necessary to speak to a doctor about this or other pelvic pain symptoms such as pain during urination ${ }^{38}$. Awareness of endometriosis in young Australian women is still relatively low, with only $52 \%$ of adolescents having heard of endometriosis, while other forms of chronic pelvic pain almost unknown, with a vanishingly small percentage of adolescents (less than $10 \%$ ) having heard of vulvodynia ${ }^{38}$. Additionally, while there is a National Action Plan for Endometriosis in Australia ${ }^{15}$ and over nine million dollars of funding has been committed to endometriosis in 2020 and beyond, there are not similar initiatives in Australia for those without endometriosis whose pelvic pain symptoms have a similar impact on their lives.

The silencing of women and lack of open discussion around their reproductive bodies can have significant consequences in critical areas of their lives. The normalisation of menstrual and sexual pain reported by our respondents is common 8,38 and results in embarrassment ${ }^{10}$, with women often suffering in silence despite regularly missing work ${ }^{39}$ or academic studies ${ }^{40}$. Across reproductive conditions, women frequently report distinct experiences of having their symptoms being dismissed, not being taken seriously or being misdiagnosed, all leading to serious implications for women's ongoing health ${ }^{41}$. Feeling dismissed by medical professionals is not uncommon in those with endometriosis ${ }^{9,42}$ or primary dysmenorrhea ${ }^{43}$, and reflects a persistent attitude, reported by our participants, that women's pain is taken less seriously or conceptualised as emotional or hysterical. Dismissive attitudes may be why so few young women, regardless of location, seek medical help for their menstrual symptoms ${ }^{44}$ and may explain why there is a two and a half year delay on average in Australian women between the onset of their pelvic pain symptoms and visiting a doctor to speak with them about these symptoms ${ }^{6}$. 
Additionally, medical practitioners' lack of understanding of the extent of pelvic pain ${ }^{45,46}$, inability to provide comprehensive biopsychosocial care $\mathrm{C}^{47}$ and physician frustrations of managing endometriosis 48 also contribute to women's negative experiences with medical professionals. Participants reported positive experiences with the health care system after finding a supportive and caring physician, with a balance of pelvic pain knowledge and sensitivity to address their concerns. Satisfaction with medical support is also dependent on information and support provided for pain management, fertility and mental health support ${ }^{49}$. Referring women with pelvic pain for holistic wellbeing with multidisciplinary professionals ${ }^{50}$ or support groups can be critical to improving their lived experiences with pelvic pain. Increasing physician and medical student understanding of how to provide patient-centred care ${ }^{51}$ for women living with pelvic pain, viewing women as experts of their own bodies, continuity of care, and shared-decision making in treatment plans can all contribute to more positive health outcomes and lived experiences of women with pelvic pain.

A strength of this study is its qualitative approach allowing for the complexity and depth of women's narratives to be explored, and the inclusion of women with lived experiences of both endometriosis, and uniquely; pelvic pain. The limitations include small sample size, particularly women with nonendometriosis related pelvic pain and that the majority of research participants were Caucasian. Future research is needed to examine experiences of women from different cultural backgrounds, where meanings associated with menstruation, sexuality, fertility, motherhood and work may differ, and where discussion surrounding such topics may be even less acceptable 52,53 .

\section{Conclusions}

Women with chronic pelvic pain reported similar impact on their lives to those with a diagnosis of endometriosis, but often felt like they had less support and information available. Normalisation of menstrual, pelvic and sexual pain in combination with the taboo nature of discussing these issues openly contributes to delays in health seeking behaviour. Delays in diagnosis, with multiple incorrect diagnoses occurring, often left women feeling like they did not have a valid illness. Most did not feel like their pain was taken seriously by health care professionals. Diagnosis was often a relief due to having a 'valid' disease but those with chronic pelvic pain often did not have a formal diagnosis and leaving them feeling like their condition is somehow less real.

\section{Declarations}

\section{Acknowledgments}

Thank you to The Pelvic Pain Foundation of Australia (PPFA), Endometriosis Australia, EndoActive, Family Planning NSW and others who assisted with recruitment.

\section{Authors' Contribution}


MA, SM and KJC conceptualised the study, MA, SM and KJC ran the focus groups, AH and HD performed the data analysis, while MA, KJC, SM and $\mathrm{AH}$ interpreted the data. MA and $\mathrm{AH}$ took the lead in drafting the manuscript, with HD, SM and KJC providing critical feedback and edits to the draft. All authors approved the final manuscript.

\section{Authors' Disclosure Statement}

MA: As a medical research institute, NICM Health Research Institute receives research grants and donations from foundations, universities, government agencies and industry. Sponsors and donors provide untied and tied funding for work to advance the vision and mission of the Institute. This study was not specifically supported by donor or sponsor funding to NICM. MA is a clinical advisory board member for Endometriosis Australia. All other authors have no disclosures.

\section{Funding}

The Pelvic Pain Foundation of Australia provided funding for this study as part of their research grants program.

\section{Ethics approval and consent to participate}

This survey was approved by the Western Sydney University Human Research Ethics Committee, approval number H12019. Participants gave written, informed consent prior to the focus groups.

\section{References}

1. Steege J, Siedhoff M: Chronic pelvic pain. Obstetrics \& Gynecology. 2014;124:616-629.

2. Kennedy S, Moore S: The initial management of chronic pelvic pain. 2012.

3. Ahangari A: Prevalence of Chronic Pelvic Pain Among Women: An Updated Review. Pain Physician. 2014;17:E141-E147.

4. Zondervan K, Yudkin P, Vessey M, et al.: The community prevalence of chronic pelvic pain in women and associated illness behaviour. British Journal of General Practice. 2001;51:541-547.

5. Evans SF: Chronic pelvic pain in Australia and New Zealand. Australian and New Zealand Journal of Obstetrics and Gynaecology. 2012;52:499-501.

6. Armour M, Sinclair J, Ng CHM, et al.: Endometriosis and chronic pelvic pain have similar impact on women, but time to diagnosis is decreasing: an Australian survey. Sci Rep. 2020;10:16253.

7. Mellado BH, Falcone AC, Poli-Neto OB, Rosa ESJC, Nogueira AA, Candido-Dos-Reis FJ: Social isolation in women with endometriosis and chronic pelvic pain. International Journal of Gynecology and Obstetrics. 2016;133:199-201.

8. Moradi M, Parker M, Sneddon A, Lopez V, Ellwood D: Impact of endometriosis on women's lives: a qualitative study. BMC women's health. 2014;14:123. 
9. Young K, Fisher J, Kirkman M: Women's experiences of endometriosis: a systematic review and synthesis of qualitative research. J Fam Plann Reprod Health Care. 2015;41:225-234.

10. Seear K: The etiquette of endometriosis: stigmatisation, menstrual concealment and the diagnostic delay. Social science \& medicine. 2009;69:1220-1227.

11. Pitts MK, Ferris JA, Smith AM, Shelley JM, Richters J: Prevalence and correlates of three types of pelvic pain in a nationally representative sample of Australian women. Medical Journal of Australia. 2008;189:138-143.

12. Rowlands I, Abbott J, Montgomery G, Hockey R, Rogers P, Mishra G: Prevalence and incidence of endometriosis in Australian women: a data linkage cohort study. BJOG: An International Journal of Obstetrics \& Gynaecology. 2020.

13. Harlow B, Stewart E: A population-based assessment of chronic unexplained vulvar pain: Have we underestimated the prevalence of vulvodynia? Journal of the American Medical Women's Association. 2003;58:82-88.

14. Reed BD, Harlow SD, Sen A, et al.: Prevalence and demographic characteristics of vulvodynia in a population-based sample. American Journal of Obstetrics and Gynecology. 2012;206:170.e171170.e179.

15. Australian Government Department of Health: National Action Plan for Endometriosis. 2018; http://www.health.gov.au/internet/main/publishing.nsf/Content/endometriosis Accessed 12/1/19.

16. Mellado BH, Pilger TL, Poli-Neto OB, Rosa ESJC, Nogueira AA, Candido Dos Reis FJ: Current usage of qualitative research in female pelvic pain: a systematic review. Arch Gynecol Obstet. 2019;300:495501.

17. Armour M, Lawson $\mathrm{K}$, Wood A, Smith CA, Abbott J: The cost of illness and economic burden of endometriosis and chronic pelvic pain in Australia: A national online survey. PLoS One. 2019;14:e0223316.

18. Braun V, Clark V: Successful qualitative research: A practical guide for beginners. London, UK: Sage Publications; 2013.

19. Young K, Fisher J, Kirkman M: Women's experiences of endometriosis: A systematic review and synthesis of qualitative research. Journal of Family Planning \& Reproductive Health Care. 2015;41:225.

20. Ayling K, Ussher JM: "If sex hurts, am I still a woman?" The subjective experience of vulvodynia in hetero-sexual women. Archives of Sexual Behavior. 2008;37:294-304.

21. Nelsen LM, Lenderking WR, Pokrzywinski R, et al.: Experience of symptoms and disease impact in patients with adenomyosis. The Patient - Patient-Centered Outcomes Research. 2018;11:319-328.

22. Chalmers KJ, Catley MJ, Evans SF, Moseley GL: Clinical assessment of the impact of pelvic pain on women. Pain. 2017;158:498-504.

23. Ponte M, Klemperer E, Sahay A, Chren MM: Effects of vulvodynia on quality of life. Journal of the American Academy of Dermatology. 2009;60:70-76. 
24. Shallcross R, Dickson JM, Nunns D, Mackenzie C, Kiemle G: Women's Subjective Experiences of Living with Vulvodynia: A Systematic Review and Meta-Ethnography. Archives of Sexual Behavior. 2018;47:577-595.

25. Simoens S, Dunselman G, Dirksen C, et al.: The burden of endometriosis: costs and quality of life of women with endometriosis and treated in referral centres. Hum Reprod. 2012;27:1292-1299.

26. Nnoaham KE, Hummelshoj L, Webster P, et al.: Impact of endometriosis on quality of life and work productivity: a multicenter study across ten countries. Fertil Steril. 2011;96:366-373 e368.

27. Cauterucci C: Embracing "the Blob"-and Other Period Euphemisms. 2016; https://slate.com/humaninterest/2016/03/euphemisms-for-periods-are-the-best.html.

28. Johnston-Robledo I, Chrisler JC: The menstrual mark: Menstruation as social stigma. Sex roles. 2013;68:9-18.

29. Hintz EA: The vulvar vernacular: Dilemmas experienced and strategies recommended by women with chronic genital pain. Health communication. 2018.

30. Shallcross R, Dickson JM, Nunns D, Mackenzie C, Kiemle G: Women's subjective experiences of living with vulvodynia: a systematic review and meta-ethnography. Arch Sex Behav. 2018;47:577-595.

31. Levitt RB, Barnack-Tavlaris JL: Addressing Menstruation in the Workplace: The Menstrual Leave Debate. In: Bobel C, Winkler IT, Fahs B, Hasson KA, Kissling EA, Roberts TA, eds. The Palgrave Handbook of Critical Menstruation Studies. Singapore: Palgrave Macmillan; 2020:561-575.

32. Parton C, Katz T, Ussher JM: 'Normal' and 'failing' mothers: Women's constructions of maternal subjectivity while living with multiple sclerosis. Health. 2017;23:516-532.

33. Parton C, Ussher JM, Natoli S, Perz J: Being a mother with multiple sclerosis: Negotiating cultural ideals of mother and child. Feminism \& Psychology. 2017;28:212-230.

34. Bassin D, Honey M: Representations of motherhood Kaplan, MM New Haven, CT: Yale University Press; 1994.

35. Endometriosis Australia: Webinars. 2020; https://www.endometriosisaustralia.org/webinars. Accessed March, 2020.

36. QENDO: Schools Program. 2020; https://www.qendo.org.au/schools-program. Accessed March 21st, 2020.

37. Armour M, Ferfolja T, Curry C, et al.: The Prevalence and Educational Impact of Pelvic and Menstrual Pain in Australia: A National Online Survey of 4202 Young Women Aged 13-25 Years. J Pediatr Adolesc Gynecol. 2020;33:511-518.

38. Armour M, Hyman MS, Al-Dabbas M, et al.: Menstrual health literacy and management strategies in young women in Australia: a national online survey of young women aged 13-25. J Pediatr Adolesc Gynecol. 2020.

39. Schoep ME, Adang EMM, Maas JWM, De Bie B, Aarts JWM, Nieboer TE: Productivity loss due to menstruation-related symptoms: a nationwide cross-sectional survey among 32748 women. BMJ Open. 2019;9:e026186. 
40. Armour M, Parry K, Manohar N, et al.: The Prevalence and Academic Impact of Dysmenorrhea in 21,573 Young Women: A Systematic Review and Meta-Analysis. J Womens Health (Larchmt). 2019;28:1161-1171.

41. Dekker RL, Morton $\mathrm{CH}$, Singleton P, Lyndon A: Women's experiences being diagnosed with peripartum cardiomyopathy: a qualitative study. Journal of midwifery \& women's health. 2016;61:467-473.

42. Young K, Fisher J, Kirkman M: Partners instead of patients: Women negotiating power and knowledge within medical encounters for endometriosis. Feminism \& Psychology. 2019;30:22-41.

43. Li AD, Bellis EK, Girling JE, et al.: Unmet Needs and Experiences of Adolescent Girls with Heavy Menstrual Bleeding and Dysmenorrhea: A Qualitative Study. J Pediatr Adolesc Gynecol. 2020;33:278284.

44. Armour M, Parry K, Al-Dabbas MA, et al.: Self-care strategies and sources of knowledge on menstruation in 12,526 young women with dysmenorrhea: A systematic review and meta-analysis. PLoS One. 2019;14:e0220103.

45. Fauconnier A, Staraci S, Huchon C, Roman H, Panel P, Descamps P: Comparison of patient-and physician-based descriptions of symptoms of endometriosis: a qualitative study. Human reproduction. 2013;28:2686-2694.

46. Grundström H, Kjølhede P, Berterö C, Alehagen S: "A challenge"-healthcare professionals' experiences when meeting women with symptoms that might indicate endometriosis. Sexual \& Reproductive Healthcare. 2016;7:65-69.

47. Young K, Fisher J, Kirkman M: Clinicians' perceptions of women's experiences of endometriosis and of psychosocial care for endometriosis. Australian and New Zealand Journal of Obstetrics and Gynaecology. 2017;57:87-92.

48. Rowe HJ, Hammarberg K, Dwyer S, Camilleri R, Fisher JR: Improving clinical care for women with endometriosis: qualitative analysis of women's and health professionals' views. Journal of Psychosomatic Obstetrics \& Gynecology. 2019:1-7.

49. Lukas I, Kohl-Schwartz A, Geraedts K, et al.: Satisfaction with medical support in women with endometriosis. PloS one. 2018;13:e0208023.

50. Rush G, Misajon R: Examining subjective wellbeing and health-related quality of life in women with endometriosis. Health care for women international. 2018;39:303-321.

51. Apers S, Dancet EA, Aarts JW, Kluivers KB, D'Hooghe TM, Nelen WL: The association between experiences with patient-centred care and health-related quality of life in women with endometriosis. Reproductive biomedicine online. 2018;36:197-205.

52. Hawkey AJ, Ussher JM, Perz J: “If you don't have a baby, you can't be in our culture”: Migrant and refugee women's experiences and constructions of fertility and fertility control. Women's Reproductive Health. 2018.

53. Hawkey AJ, Ussher JM, Perz J, Metusela C: Experiences and constructions of menarche and menstruation among migrant and refugee women. Qualitative Health Research. 2017;27:1473-1490. 